\title{
Exploring the Most Promising Stem Cell Therapy in Liver Failure: A Systematic Review
}

\author{
Jeanne AdiwinataPawitan $\mathbb{D}^{1,2,3}$ \\ ${ }^{1}$ Department of Histology, Faculty of Medicine Universitas Indonesia, Jakarta, Indonesia \\ ${ }^{2}$ Stem Cell Medical Technology Integrated Service Unit, Dr.CiptoMangunkusumo General Hospital/Faculty of Medicine \\ Universitas Indonesia, Jakarta, Indonesia \\ ${ }^{3}$ Stem Cell and Tissue Engineering Research Center, Indonesia Medical Education and Research Institute (IMERI), Faculty of \\ Medicine Universitas Indonesia, Jakarta, Indonesia \\ Correspondence should be addressed to Jeanne AdiwinataPawitan; jeanneadiwip@gmail.com
}

Received 7 July 2019; Revised 9 September 2019; Accepted 17 September 2019; Published 1 December 2019

Academic Editor: Francisco J. Rodríguez-Lozano

Copyright (C) 2019 Jeanne AdiwinataPawitan. This is an open access article distributed under the Creative Commons Attribution License, which permits unrestricted use, distribution, and reproduction in any medium, provided the original work is properly cited.

\begin{abstract}
Background. Alternative approaches to transplantation for liver failure are needed. One of the alternative approaches is stem cell therapy. However, stem cell therapy in liver failure is not standardized yet, as every centre have their own methods. This systematic review is aimed at compiling and analyzing the various studies that use stem cells to treat liver failure, to get an insight into potential protocols in terms of safety and efficacy by comparing them to controls. Methods. This systematic review was done according to PRISMA guidelines and submitted for registration in PROSPERO (registration number CRD42018106119). All published studies in PubMed/MEDLINE and Cochrane Library, using key words: "human" and "stem cell" AND "liver failure" on $16^{\text {th }}$ June 2018, without time restriction. In addition, relevant articles that are found during full-text search were added. Inclusion criteria included all original articles on stem cell use in humans with liver failure. Data collected included study type, treatment and control number, severity of disease, concomitant therapy, type and source of cells, passage of cells, dose, administration route, repeats, and interval between repeats, outcomes, and adverse events compared to controls. Data were analyzed descriptively to determine the possible causes of adverse reactions, and which protocols gave a satisfactory outcome, in terms of safety and efficacy. Results. There were 25 original articles, i.e., eight case studies and 17 studies with controls. Conclusion. Among the various adult stem cells that were used in human studies, MSCs from the bone marrow or umbilical cord performed better compared to other types of adult stem cells, though no study showed a complete and sustainable performance in the outcome measures. Intravenous (IV) route was equal to invasive route. Fresh or cryopreserved, and autologous or allogeneic MSCs were equally beneficial; and giving too many cells via intraportal or the hepatic artery might be counterproductive.
\end{abstract}

\section{Introduction}

The gold standard therapy for liver failure is liver transplant. However, there are discrepancies between liver supply and demand for transplantation. In the USA, Habka et al. stated that from 16,000 patients who were registered to receive liver transplantation, only $38 \%$ could get the transplant [1]. More- over, the number of patients who need a liver transplant is on the rise each year, which in 2016 the rise in demand was $10 \%$ compared to the demand in 2015 [2]. Limited numbers of donors and transplant rejections are problems that liver failure patients have to face. A study on adult living donor transplantation showed that the hazard ratio for chronic and acute rejection was $6.93(p=0.006)$ and $2.96(p=0.017)$, 
respectively [3]. Attempts to increase the potential of altruistic organ donation through social media is promising, but not without problems, as there is a possibility that a potential living donor may become a victim of inappropriate social media campaign [4].

Therefore, alternative approaches other than transplantation are needed. One of the alternative approaches is stem cell therapy. However, stem cell therapy in liver failure is not standardized yet, as every centre have their own methods, in terms of the type of cells, the dose, route, and outcome measures to assess the success of therapy. This systematic review is aimed at compiling and analyzing the various studies that use adult stem cells to treat liver failure, to get an insight into potential protocols in terms of safety and efficacy by comparing them to controls.

\section{Materials and Methods}

This systematic review was done according to preferred reporting items for systematic review (PRISMA) guidelines and submitted for registration in PROSPERO (registration number CRD42018106119). All published studies in PubMed/MEDLINE and Cochrane Library, using key words: "human" and "stem cell" AND "liver failure" on $16^{\text {th }}$ June 2018, without time restriction. In addition, relevant articles that are found during full-text search were added.

2.1. Inclusion Criteria. All original articles on adult stem cell use in humans with liver failure were included. Exclusion criteria included articles in the non-English literature such as Chinese and German language, and studies on stem cell therapy in liver failure that did not assess both the adverse events and any of common liver failure study outcomes, i.e., liver failure symptoms and signs (ascites, lower limb edema, and jaundice), lab findings (albumin, alanine aminotransferase (ALT), aspartate aminotransferase (AST), total bilirubin, direct bilirubin, prothrombin time and concentration), or liver failure complications (hematemesis, melena, encephalopathy). Also studies that gave granulocyte-macrophage colony-stimulating factor (GM-CSF) only without stem cells were excluded.

Data collected includes type of study, number of participant, number of treatments and controls, severity of disease, concomitant therapy besides of stem cell therapy, type and source of cells, passage of cells, dose, vehicle type, vehicle amount, administration route, repeats, and interval between repeats, outcomes, and adverse events compared to controls.

2.2. Data Analysis. The studies were grouped and tabulated according to types of studies, which were divided into case studies (studies without control) and controlled clinical trials. Further, the number of cases, and outcome-related variables, i.e., type and source of cells, passage, dose, combination with other therapies and outcome were tabulated. In addition, stem cell therapy adverse reaction-related variables, i.e., cell type and sourc, vehicle type and volume, route of administration, and adverse reaction, were also tabulated.

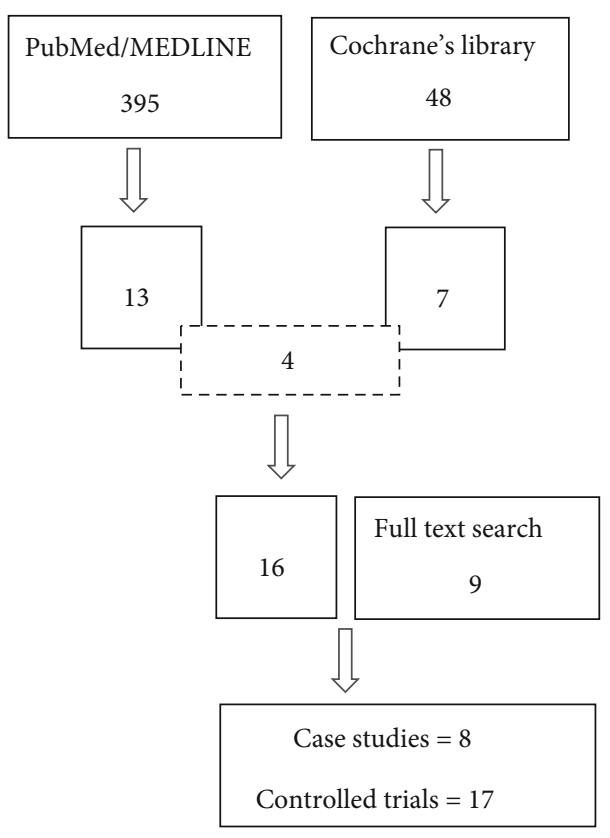

Figure 1: Literature search result.

Data were analyzed descriptively to determine the possible causes of adverse reactions, and which protocols gave a satisfactory outcome, in terms of safety and efficacy. Further animal studies and pluripotent cell-derived cell therapy were discussed.

\section{Results and Discussion}

3.1. Results. From PubMed/MEDLINE, we found 395 articles and from Cochrane's library, 48 articles, out of which there were 13 and seven eligible articles from PubMed/MEDLINE and Cochrane's library, respectively, where four articles were found in both (overlapping). In addition, there were nine articles that were found during full-text search. So altogether, there were 25 original articles (Figure 1). Of these articles, 8 studies did not have controls and were classified as case studies (Table 1) [5-12], while 17 studies had controls (randomized and non-randomized clinical trials Table 2) [13-29]. Figure 2 shows country distribution of adult stem cell therapy for liver failure.

3.2. Discussion. The eight case studies included variable numbers of patients, from one to 17 patients, and mostly (seven case studies) used various autologous stem cells, i.e., bone marrow- (BM-) mesenchymal stem cells (MSCs) (3 studies) and the rest used peripheral blood (PB) CD133, PB-CD34, CD34-depleted BM-mononuclear cells (MNCs), or BMCD34 [5-11]. Only one study used allogeneic umbilical cord(UC-) MSCs [12]. Moreover, there were 17 studies that included 25 to 158 cases and compared stem cell treatments to controls, which used various autologous stem cells, i.e., BM-MSCs (six studies) [13-18], BM-MSC-derived hepatic lineage (one study) [19], BM-MNCs/BM CD133 [20], BM CD34 and CD133 [21], BM-MNCs [22], PB-CD34 (two studies) $[23,24]$, and allogeneic stem cells, i.e., BM-MSCs 


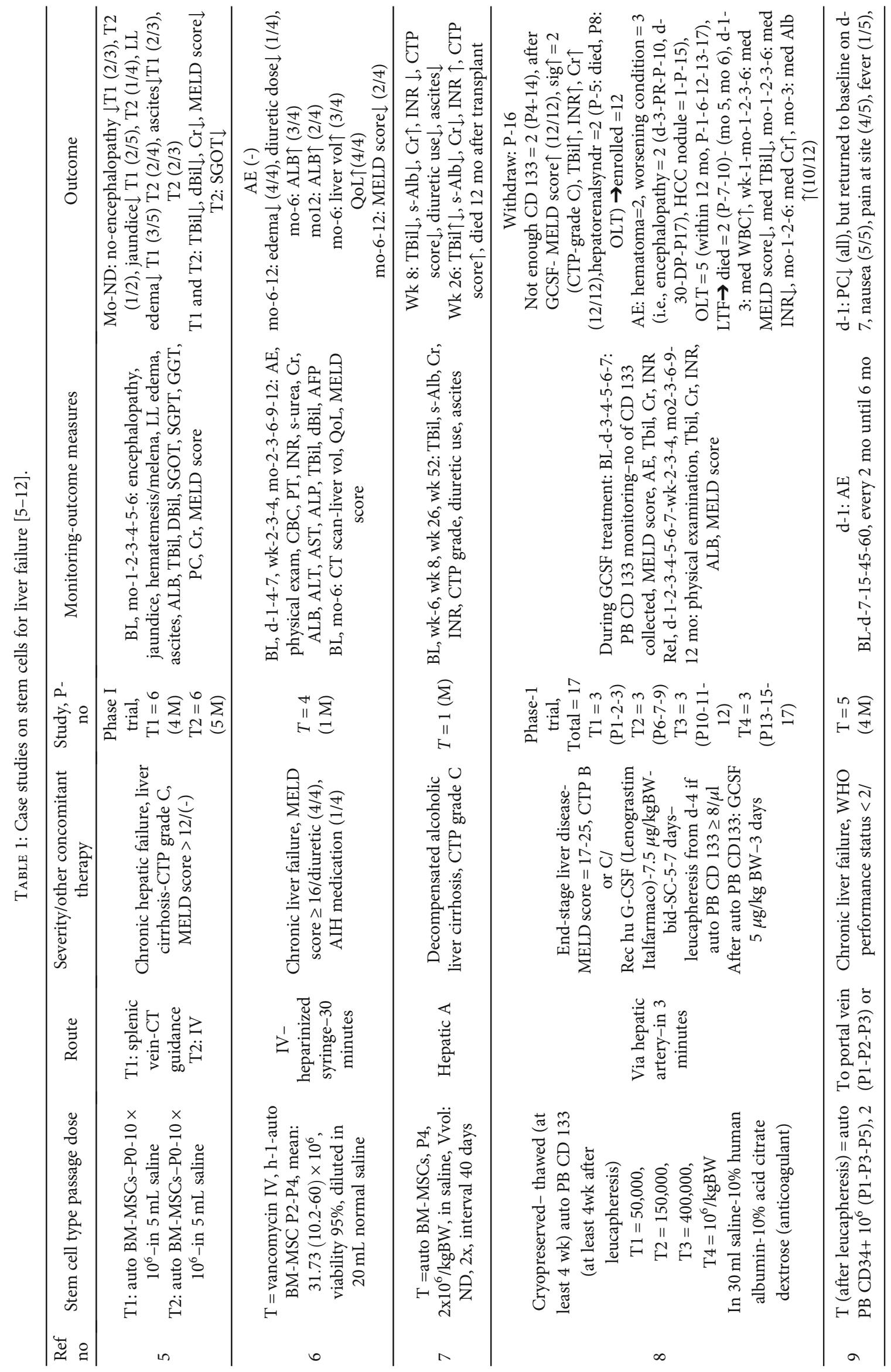




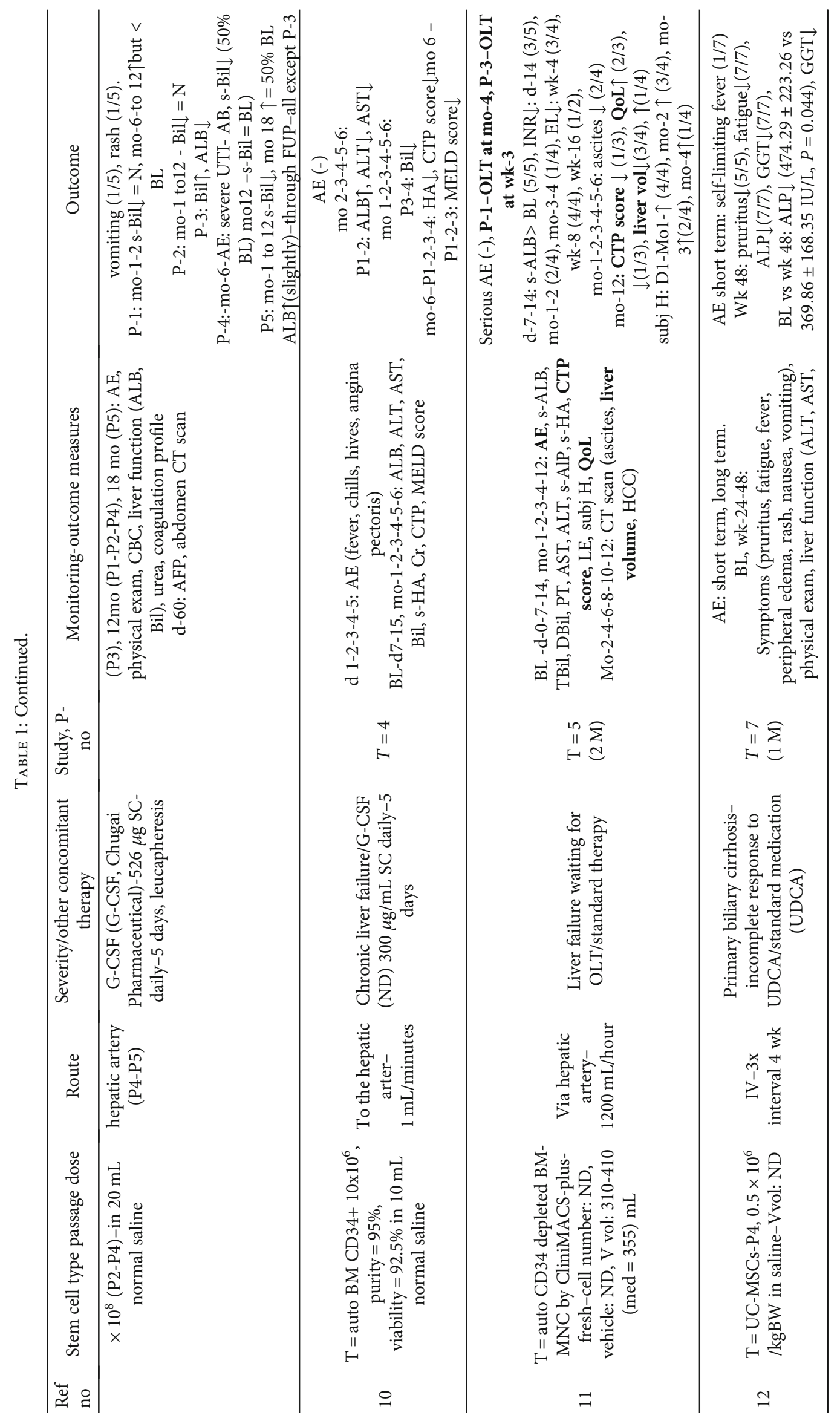




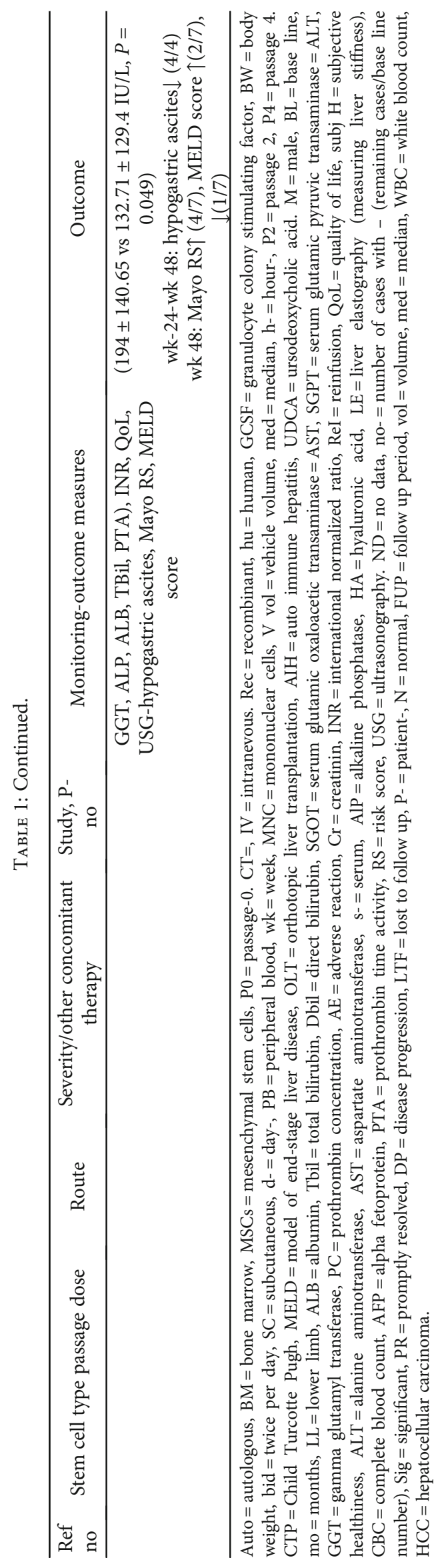




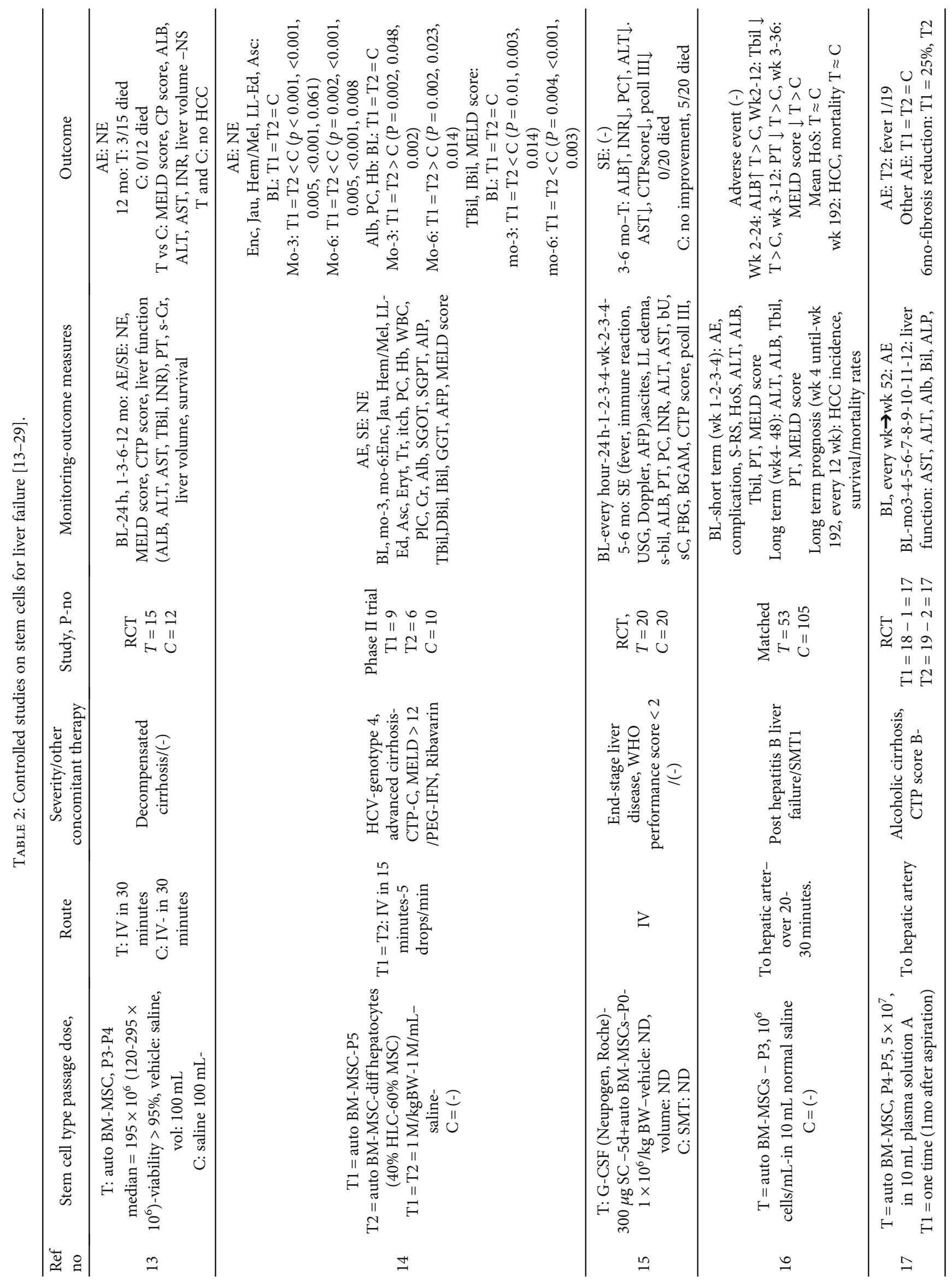




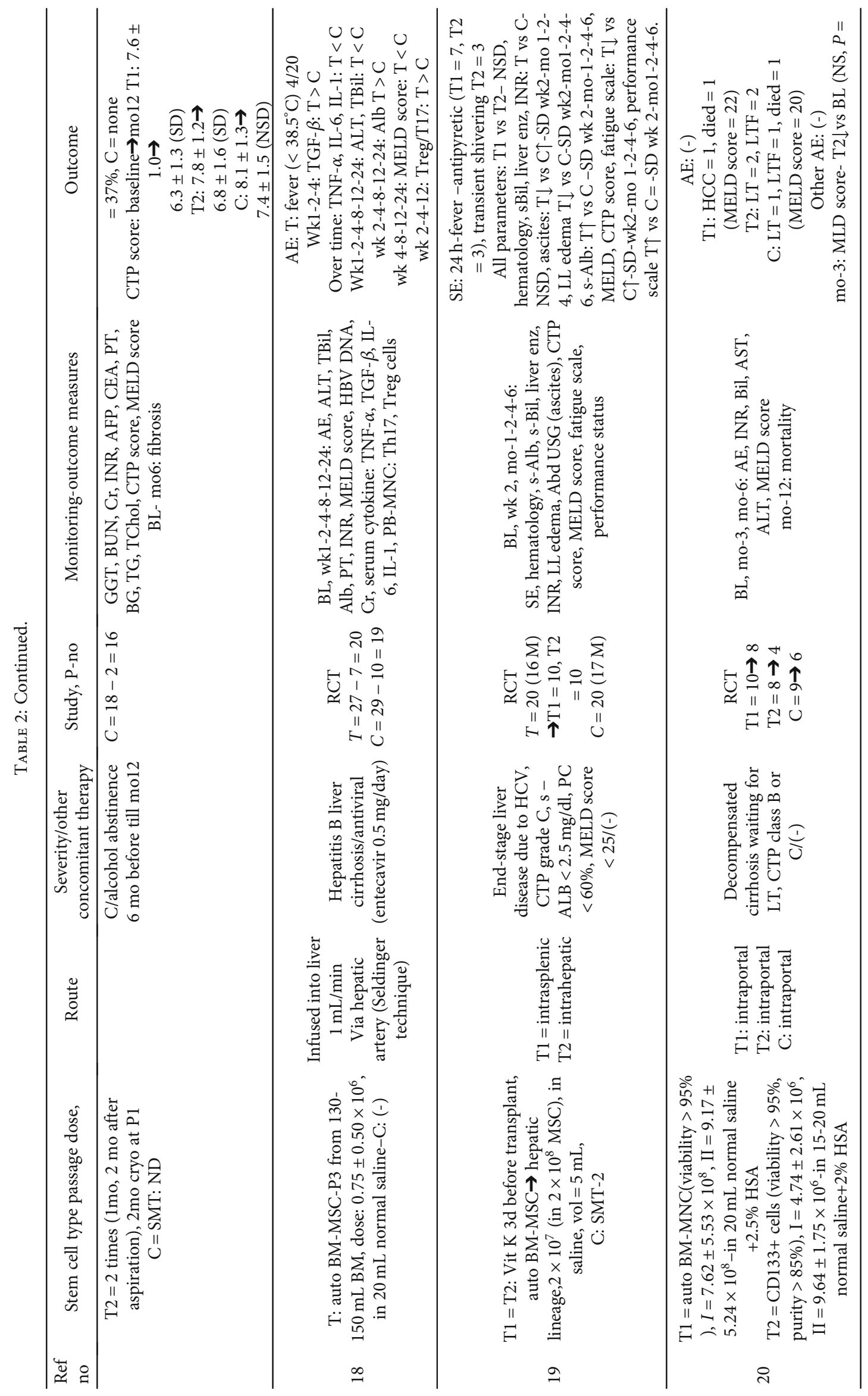




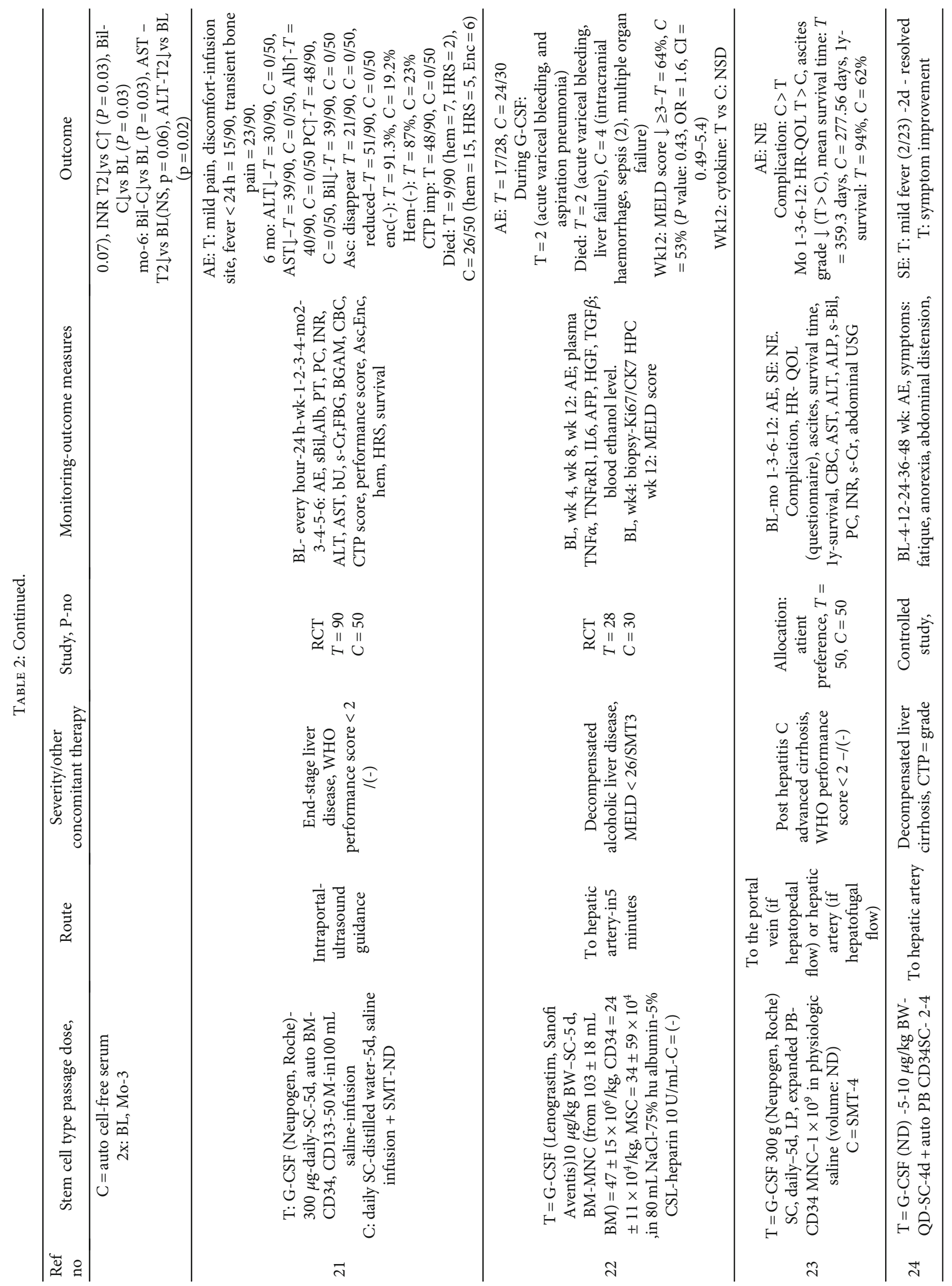




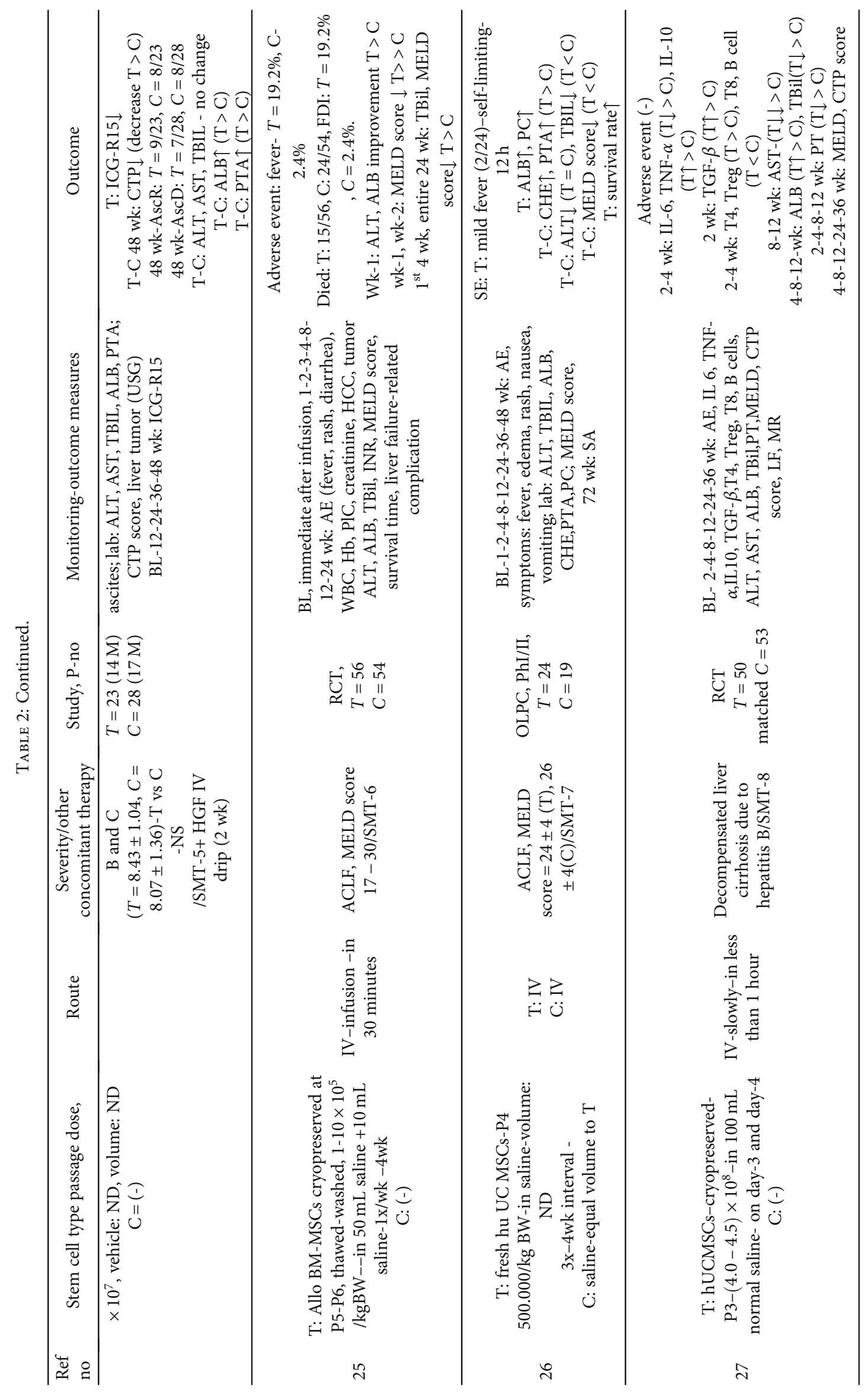




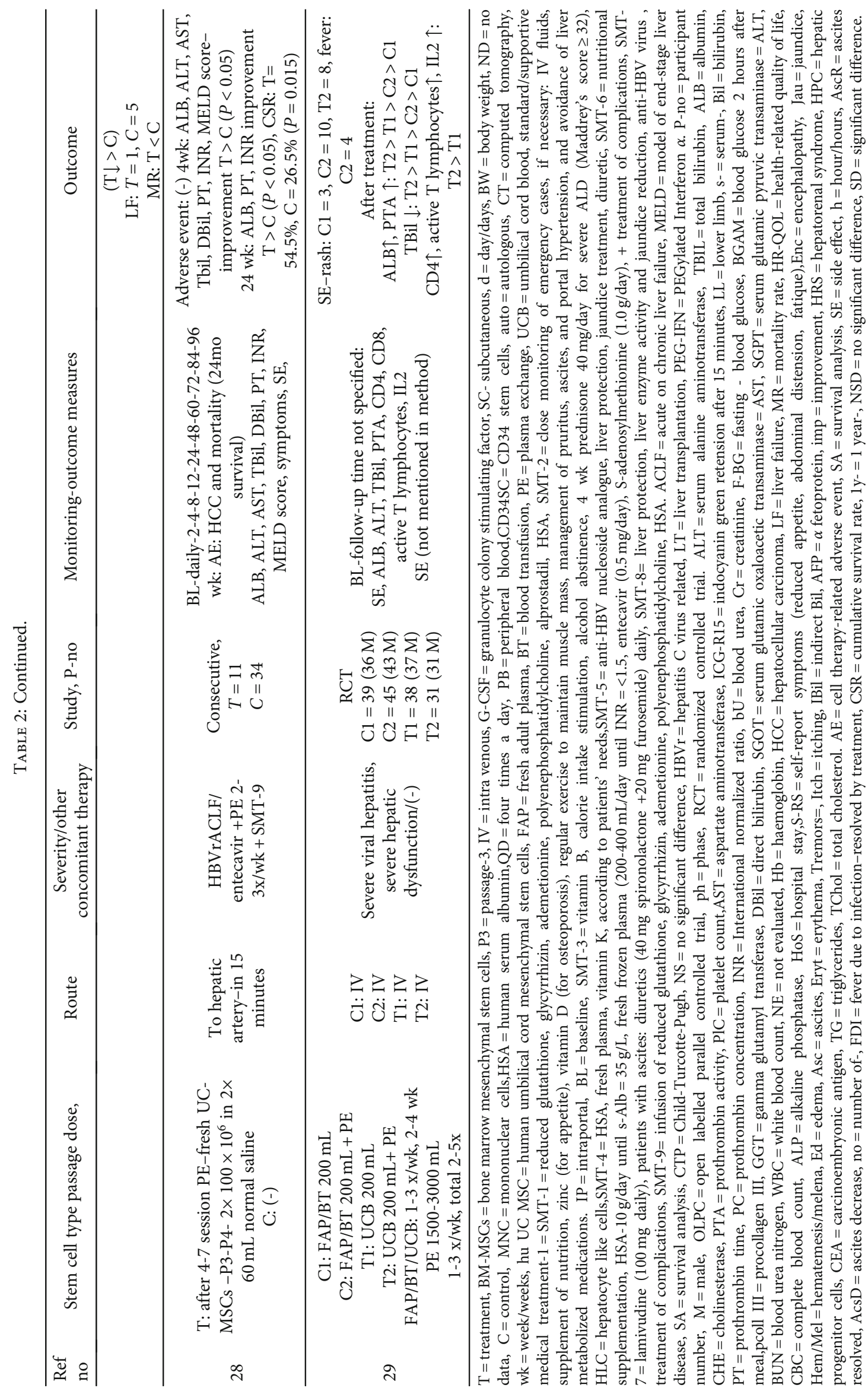


Adult stem cell therapy for liver failure

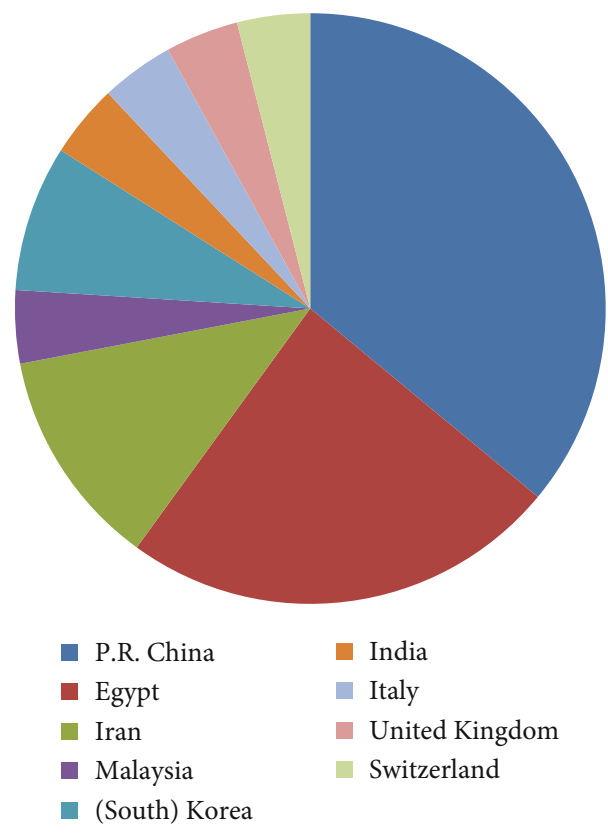

Figure 2: Country distribution of adult stem cell therapy for liver failure.

[25], UC-MSCs (three studies) [26-28], and stem cell containing umbilical cord blood (UCB) [29]. Moreover, inclusion and exclusion criteria, cell dose, route of administration, concomitant therapies, and outcome measures differed between those studies, which caused a systematic review was more appropriate than meta-analysis.

3.3. Safety of Adult Stem Cell Therapy in Liver Failure. Case studies without G-CSF administration and/or leucapheresis did not show any serious adverse events that were related to stem cell therapy $[5-7,11,12]$ (Table 1 ), the same applied to controlled studies without G-CSF administration, where cell therapy-related adverse events were recorded and adverse events in treatments were equal or less compared to controls [16-19]. Further, there was no stem cell-related adverse event in the use of allogeneic MSCs [25-28], and stem cell containing UCB [29] (Table 2). However, a controlled study showed that one out of ten cases who received BM-MNC administration developed hepatocellular carcinoma, compared to none in the control, or those received CD133 cells [20].

Most case studies that used granulocyte colonystimulating factor (G-CSF) administration did not show any serious stem cell-related adverse events $[9,10]$; and controlled studies with G-CSF administration in treatment arm did not show any difference in adverse event occurrence between treatments and controls [15, 21-24]. However, several case studies that used PB stem cells $[8,9]$ following G-CSF administrationand CD133 [8] or CD34 collection [9] by leucapheresis showed that all cases either experienced increased model of end-stage liver disease (MELD) score and creatinine after G-CSF administration [8], or decrease platelet count at day-1 that returned to baseline at day-7 after G-CSF administration and leucapheresis [9]. Further, a controlled study that used BM-MNC following G-CSF administration showed acute variceal bleeding and aspiration pneumonia [22].

However, administration of G-CSF in another case study that used BM-CD34 [10] and administration of G-CSF in controlled studies that used BM-MSCs [15], BMCD34/CD133 [21], and PB-CD34 [23, 24] did not show any G-CSF-related adverse event.

In a case study to assess the safety of various doses, higher doses of thawed PB-CD133 after cryopreservation (150,000, 400,000 , and $10^{6} / \mathrm{kg}$ body weight (BW)) showed a more worsening condition (encephalopathy, hepatocellular carcinoma, and death compared to lower doses $(50,000 / \mathrm{kg} \mathrm{BW})$ [8].

In the case studies, only two studies used IV route only [6, 12], while the other six used invasive application to the hepatic artery (four studies) $[7,8,10,11]$, or to splenic/IV (one study) [5]) or to the hepatic artery/portal vein (one study) [9].In controlled studies, seven studies used IV route [13-15, 25-27, 29], while other studies used invasive application via the hepatic artery (six studies) [16-18, 22, 24, 28], intrasplenic/intrahepatic (one study) [19], intraportal (two studies) [20, 21], and intraportal/intrahepatic [23]. There was no serious adverse event that was related to invasive route of application. Though IV is the easiest and safest way of administration and does not need special expertise in choosing the most effective way of administration, the results need to be considered. However, comparing the results of various routes of applications was inappropriate, as the studies used different types and/or dose of stem cells, except for two case series that compared either intravenous (IV) and splenic vein application [5] or the portal vein and hepatic artery application [9], and a controlled study that compared intrasplenic and intrahepatic route [19]. In a case series and a controlled study, compared applications showed more or less the same improvement $[5,19]$. However, in another case study, one out of three cases, who got PBCD34 administration through a portal vein showed worsening condition of the liver function, which did not occur in administration through the hepatic artery [9].

3.4. Efficacy of Adult Stem Cell Therapy in Liver Failure. Efficacy of stem cell therapy in liver failure was assessed in eight case studies without controls (Table 1) and 17 controlled trials (Table 2). However, case studies without controls lack of rigor, as the improvements might be due to placebo effects, or might be the natural course of disease, as some studies gave additional treatment other that stem cell therapy. Therefore, efficacy is more appropriate to be concluded from controlled trials, and case studies/series are more appropriate for safety studies.

3.4.1. Case Studies/Series Using Adult Stem Cells. Table 1 showed that three case studies transplanted BM-MSCs at various passages ( $\mathrm{P} 0$ to $\mathrm{P} 4$ ), and various numbers of BM-MSCs, i.e., from $10 \times 10^{6}$ (total number) to $2 \times 10^{6} / \mathrm{kg} \mathrm{BW}$ [5-7]. Most BM-MSC studies showed some improvements; one case series with application via splenic vein or IV [5] was 
followed up until 6 months and showed improvements in almost all parameters, including decrease in MELD score in part of the cases. Another case series [6] with IV application was followed up until 12 months and showed improvements in albumin level, including MELD score that were preserved until 12 months in half of the cases, while a case report [7] with application to the hepatic artery showed improvement at week-8, but then at week-26 onward improvement decreased and died 12 months after stem cell transplantation.

A case study that used PB CD133 stem cells showed that some cases of all doses experienced a decrease in MELD score and total bilirubin only between wk-1 to wk-6 [8], while another case study that used PB CD 34 showed that some cases of all doses experienced serum bilirubin reduction and albumin level increase [9].

A case study that used BM-CD34, where all cases were followed up until 6 months showed some improvement in some though not all parameters, and at month- 6 all cases showed reduced Child-Turcotte-Pugh (CTP) score, and $75 \%$ of cases showed reduced MELD score [10].

A case study that used CD34-depleted BM-MNC that was followed up until 12 months showed that the best result was improvement in the albumin level of all cases, but only until day-14, which improvement gradually decreased, except in one out of three remaining cases who also showed decreased CTP score at month-12 [11].

A study that used allogeneic UC-MSCs that was followed up until 12 months showed that improvement was only on gamma glutamyl transferase (GGT) and alkaline phosphatase (ALP) level that occurred in all cases and reduced ascites in all four ascites cases until 12 months [12].

3.4.2. Clinical Trials with Controls Using Adult Stem Cells. Table 2 showed that from 17 controlled trials, a randomized controlled trial (RCT) that gave 120-295 × 10 6 BM-MSCs via IV route showed no beneficial effect of stem cell therapy compared to control [13], but two other (phase-2 controlled trial and RCT) that gave the same cells and via the same route showed improvement in some of the parameters including reduced MELD Score [14], or CTP score [15]. Both studies that showed improvement used lower number of cells, i.e., $10^{6}$ cells/kg BW. The three studies using BM-MSCs via IV route differed in inclusion criteria of the cases, where the first study was on post hepatitis B liver failure [13], the second was on hepatatitis $\mathrm{C}$ virus- ( $\mathrm{HCV}$-) genotype 4 advanced cirrhosis with CTP score C and MELD score $>12$ and was given PEG-IFN and Ribavarin [14], and the third was on end-stage liver disease, WHO performance score $<2$ [15].Severity of disease and cell number might play a role in the result, where stem cell therapy might benefit for less severe disease, and too many cells might be deleterious. Moreover, concomitant therapy that aimed at the cause, such as the use of antiviral, might be beneficial.

Further, a matched controlled trial and two RCTs gave a dose of $10 \times 10^{6}, 50 \times 10^{6}$, and around $1 \times 10^{6}$ BM-MSCs, respectively, via the hepatic artery [16-18], and two out of the three trials on post hepatitis B liver failure that was concomitantly given standard supportive therapy and hepatitis B liver cirrhosis that was given entecavir showed improvement in most of the parameters including MELD score decrease $[16,18]$, while the other one on alcoholic cirrhosis with CTP score B or C and alcohol abstinence only showed improvement in CTP score and fibrosis [17].These three trials showed that concomitant therapy to stem cell therapy might be beneficial to enhance the effect of cell therapy.

An RCT on end-stage liver disease due to hepatitis $\mathrm{C}$ virus $(\mathrm{HCV}$ ) with $\mathrm{CTP}$ grade $\mathrm{C}$, serum albumin $<2.5 \mathrm{mg} / \mathrm{dl}$, prothrombin concentration $(\mathrm{PC})<60 \%$, and MELD score $<$ 25 used BM-MSC-derived hepatic lineage $\left(20 \times 10^{6}\right.$ hepatic lineage cells in $200 \times 10^{6}$ BM-MSCs) that was given intrahepatic or intrasplenic showed no difference between the two routes, and showed partial improvement including CTP and MELD score compared to controls [19].

Two RCTs that used BM-MNCs with a total dose of $1000 \times 10^{6}$ and a dose of $50 \times 10^{6} / \mathrm{kg} \mathrm{BW}$, which was given intraportal and the hepatic artery, respectively, showed no benefit compared to control $[20,22]$, but when BM-MNCs were enriched for CD133 with a dose of around $5 \times 10^{6}$ [20] or CD34/CD133 with a dose of $55 \times 10^{6}$ [21], there were partial improvements $[20,21]$. It seems that using too many BM-MNCs intraportal or intrahepatic is counterproductive, but when they are enriched to reduce the cell number, they are more beneficial. Two non-RCTs that used CD34enriched PB-MNCs with a dose of $1000 \times 10^{6}$ and $20-40 \times$ $10^{6}$ that were given intraportal or the hepatic artery showed partial improvements compared to controls [23, 24].

Four studies that used allogeneic MSCs [25-28] and an RCT that used umbilical cord blood (UCB) [29] showed various grades of improvements. An RCT on acute on chronic liver failure (ACLF) with MELD score 17-30 used cryopreserved allogeneic BM-MSCs with a dose of $1-10 \times 10^{5} / \mathrm{kg}$ BW via IV route and concomitant standard therapy showed improvements in some parameters including MELD score [25]. Three controlled trials used fresh $[26,28]$ or cryopreserved [27] UC-MSCs with a dose of $5 \times 10^{5} / \mathrm{kg} \mathrm{BW}$ via IV route [26], a dose of $450 \times 10^{6}$ via IV route [27], or a dose of $200 \times 10^{6}$ via the hepatic artery [28], all with concomitant standard therapy, where two controlled trials showed improvements in most parameters $[27,28]$, while another one showed improvements in only some of the parameters including MELD score [26]. Allogeneic use of stem cells might need to be cryopreserved to match the availability of cells and patients, and the studies above showed that cryopreserved cells might be equal to fresh cells $[27,28]$, and both IV or invasive application via the hepatic artery might be equal [27, 28].

One RCT used stem cell containing UCB compared with blood transfusion once to three times a week, with a total transfusions of two to five times, and showed partial improvements compared to control [29].

3.5. Animal Studies on Stem Cell Therapy for Liver Failure/Cirrhosis. Various animal study showed beneficial effect of adult stem cells to treat liver damage and failure [30-33].

A study used bone marrow-derived mesenchymal stem cells (BM-MSCs) infusion to treat ConA-induced liver 
damage in mice showed that the BM-MSCs were found in the liver and liver damage was reduced. Moreover, the transplanted BM-MSCs caused improvement in immune function by suppression of intrahepatic natural killer $\mathrm{T}$ cells, which previously induced liver damage upon ConA treatment [30]. Another study used intraparenchymal liver injection of human or rat adipose-derived mesenchymal stem cells (AD-MSCs) to treat rat models of acute-on-chronic liver failure and showed improvements in liver failure symptoms including ascites, hepato- and splenomegaly, and serum liver biochemical parameters [31]. A recent study used BM-MSCs and colony-stimulating factor-1-induced bone marrowderived macrophages (id-BMMs), either alone or in combination, to treat carbon tetrachloride- (CCl4-) induced cirrhosis in mice. All kinds of treatment showed beneficial effects in terms of liver fibrosis reduction, which was due to matrix metalloproteinase (MMP-9, MMP-13) secretion, decrease in liver enzyme levels in blood, and increase in hepatocyte proliferation, but the most effective treatment was obtained by combination therapy [32]. Moreover, a study compared intravenous and intrasplenic administration of BM-MSCs to CCL4 induced liver fibrosis in rats and found that both routes showed similar improvements in liver functions, but intravenous route showed better reduction in IL- $1 \beta$, IL-6, and INF- $\gamma$ [33].

\subsection{Pluripotent Stem Cell-Derived Cell Therapy for Liver} Failure/Cirrhosis. To regenerate damaged liver tissue, hepatocytes are an option for cell therapy. As hepatocytes cannot be expanded in vitro, production of hepatocytes from infinitely self-renewable pluripotent stem cells (PSCs), namely embryonic stem cells (ESCs) or induced pluripotent stem cells (iPSCs) that were initially developed by Takahashi and Yamanaka [34], is an important solution. Many studies developed protocols to induce PSCs into hepatocytes, though most of the hepatocytes were more similar to immature hepatocytes, and therefore were called hepatocyte-like cells (HLCs) [35] Some of the studies used combination of growth factors that were given in a sequential manner [36, 37], or combination of transduction factors (FOXA2 and HNF1alpha) [38]. In addition, a study used extracellular matrix laminin to induce ESCs into HLCs [39], and another study used a chemically defined culture medium to induce ESCs into HLCs [40].

Recently, a study succeeded to develop hepatocytes from human pluripotent stem cells in a current good manufacturing practice (cGMP) setting that are compliant for cell therapy. The study used two human iPSC and one ESC cGMP lines to generate functional hepatocytes using a highly reproducible protocol. The protocol used chemically defined media and consisted of four steps to produce immature progenitor of hepatocytes in 21 days, followed by seeding the immature progenitor on a scaffold made from 3D poly(ethylene glycol)-diacrylate hydrogel lattice to induce the maturation into hepatocytes. These hepatocytes were tested on immune-competent mice and were showed to be viable and functional [41].

3.7. Mechanism of Action of Liver Failure Healing in Adult Stem Cell Therapy. From the various kinds of stem cells, most studies using MSCs either from the bone marrow [14-16, 18, 25] or umbilical cord [26-28] showed the most promising results, especially when combined with concomitant standard/supporting therapy [14, 16, 18, 25-28].

MSCs are stromal cells that can be differentiated into hepatic lineage [19], though most studies showed that in stem cell therapy, most stem cells did not differentiate into the needed cells to replace damaged cells except in several conditions such as bone repair [42]; instead stem cells mostly work through paracrine effect [42]. MSC paracrine effect was shown to target hepatic stellate cells to reduce fibrosis [43], and this effect was also shown in a randomized controlled trial that found $25 \%$ and $37 \%$ reduction of fibrosis in treatment groups that received autologous BM-MSCs in a dose of $5 \times 10^{7}$ cells via the hepatic artery as once and twice administration, respectively [17].

This review showed that IV route was equal to invasive application via the hepatic artery $[19,27,28]$ or the splenic artery [5] and was safer compared to portal vein delivery [9] that deliver the stem cells directly to the liver. These findings might be due to the fact that when MSCs are delivered via IV route, after 30 minutes they are trapped in the liver, spleen, and lungs, and after 90 minutes they are in the liver, spleen, and bone marrow [44]. When MSCs home to liver, they can send mitochondria-containing tunneling nanotubes to their surrounding damaged hepatocytes to repair the damage [42]. For MSCs that are trapped in other area/organs other than liver, they can communicate with the damaged hepatocytes in the liver from afar by means of extracellular vesicles (microvesicles and exosomes) and send beneficial factors such as cytokines and growth factors including hepatocyte growth factors (HGF) to heal the damaged hepatocytes $[42,45]$ or to act on resident stem cells to differentiate and to replace the damaged hepatocytes.

Both autologous [14-16, 18] and allogeneic [25-28] MSCs were beneficial and did not show any cell-related adverse event. MSCs lack human leucocyte antigen (HLA)DR and T cell costimulatory molecules [46, 47]; therefore, allogeneic MSCs are regarded relatively safe for large number systemic infusion even they are not HLA matched.

Overall, none of the studies showed a complete and sustainable performance in the outcome measures. Moreover, various types of cells, various doses, and various routes were used, which need more studies on the quality of the cells, as well as the safety and efficacy of the therapy in well-designed clinical trials that is compliant with government regulation for cell therapy in the countries where the trials are conducted.

\section{Conclusion}

Among the various adult stem cells that were used in human studies, MSCs from the bone marrow or umbilical cord performed better compared to other types of adult stem cells, though no study showed a complete and sustainable performance in the outcome measures. IV route was equal to invasive route. Fresh or cryopreserved, and autologous or allogeneic MSCs were equally beneficial; and giving too many cells via intraportal or the hepatic artery might be counterproductive. 


\section{Data Availability}

All data were taken from the reference list.

\section{Conflicts of Interest}

None is declared.

\section{Acknowledgments}

This work was supported by a research grant from the Ministry of Research, Technology and Higher Education of the Republic of Indonesia, Hibah Penelitian Pengembangan 2019, contract no.NKB-1804/UN2.R3.1/HKP.05.00/2019.

\section{References}

[1] D. Habka, D. Mann, R. Landes, and A. Soto-Gutierrez, "Future economics of liver transplantation: a 20-year cost modeling forecast and the prospect of bioengineering autologous liver grafts," PLoS One, vol. 10, no. 7, article e0131764, 2015.

[2] W. R. Kim, J. R. Lake, J. M. Smith et al., "OPTN/SRTR 2016 Annual Data Report: Liver," American Journal of Transplantation, vol. 18, Supplement 1, pp. 172-253, 2018.

[3] D. Imai, T. Yoshizumi, K. Sakata et al., "Long-term outcomes and risk factors after adult living donor liver transplantation," Transplantation, vol. 102, no. 9, pp. e382-e391, 2018.

[4] K. Baboolal, "Crowd sourcing for organs: a social dilemma," Transplantation, vol. 102, no. 9, pp. 1405-1406, 2018.

[5] M. El-Ansary, S. Mogawer, I. Abdel-Aziz, and S. AbdelHamid, "Phase I trial: mesenchymal stem cells transplantation in end stage liver disease," Journal of American Science, vol. 6, no. 12, pp. 135-144, 2010.

[6] M. Mohamadnejad, K. Alimoghaddam, M. Mohyeddin-Bonab et al., "Phase 1 trial of autologous bone marrow mesenchymal stem cell transplantation in patients with decompensated liver cirrhosis," Archives of Iranian Medicine, vol. 10, no. 4, pp. 459466, 2007.

[7] R. Rajaram, B. Subramani, B. J. J. Abdullah, and S. Mahadeva, "Mesenchymal stem cell therapy for advanced liver cirrhosis: a case report," JGH Open, vol. 1, no. 4, pp. 153-155, 2017.

[8] P. Andreone, L. Catani, C. Margini et al., "Reinfusion of highly purified $\mathrm{CD}_{133^{+}}$bone marrow-derived stem/progenitor cells in patients with end-stage liver disease: a phase I clinical trial," Digestive and Liver Disease, vol. 47, no. 12, pp. 1059-1066, 2015.

[9] N. Levičar, M. Pai, N. A. Habib et al., "Long-term clinical results of autologous infusion of mobilized adult bone marrow derived CD $34^{+}$cells in patients with chronic liver disease," Cell Proliferation, vol. 41, Supplement 1, pp. 115-125, 2008.

[10] A. A. Khan, N. Parveen, V. S. Mahaboob et al., "Safety and efficacy of autologous bone marrow stem cell transplantation through hepatic artery for the treatment of chronic liver failure: a preliminary study," Transplantation Proceedings, vol. 40, no. 4, pp. 1140-1144, 2008.

[11] C. H. Park, S. H. Bae, H. Y. Kim et al., "A pilot study of autologous CD34-depleted bone marrow mononuclear cell transplantation via the hepatic artery in five patients with liver failure," Cytotherapy, vol. 15, no. 12, pp. 1571-1579, 2013.

[12] L. Wang, J. Li, H. Liu et al., "A pilot study of umbilical cordderived mesenchymal stem cell transfusion in patients with primary biliary cirrhosis," Journal of Gastroenterology and Hepatology, vol. 28, Supplement 1, pp. 85-92, 2013.

[13] M. Mohamadnejad, K. Alimoghaddam, M. Bagheri et al., "Randomized placebo-controlled trial of mesenchymal stem cell transplantation in decompensated cirrhosis," Liver International, vol. 33, no. 10, pp. 1490-1496, 2013.

[14] M. El-Ansary, I. Abdel-Aziz, S. Mogawer et al., "Phase II trial: undifferentiated versus differentiated autologous mesenchymal stem cells transplantation in Egyptian patients with HCV induced liver cirrhosis," Stem Cell Reviews, vol. 8, no. 3, pp. 972-981, 2012.

[15] H. Salama, A. R. N. Zekri, E. Medhat et al., "Peripheral vein infusion of autologous mesenchymal stem cells in Egyptian HCV-positive patients with end-stage liver disease," Stem Cell Research \& Therapy, vol. 5, no. 3, p. 70, 2014.

[16] L. Peng, D. Y. Xie, B. L. Lin et al., “Autologous bone marrow mesenchymal stem cell transplantation in liver failure patients caused by hepatitis B: short-term and long-term outcomes," Hepatology, vol. 54, no. 3, pp. 820-828, 2011.

[17] K. T. Suk, J.-H. Yoon, M. Y. Kim et al., "Transplantation with autologous bone marrow-derived mesenchymal stem cells for alcoholic cirrhosis: Phase 2 trial," Hepatology, vol. 64, no. 6, pp. 2185-2197, 2016.

[18] L. Xu, Y. Gong, B. Wang et al., "Randomized trial of autologous bone marrow mesenchymal stem cells transplantation for hepatitis B virus cirrhosis: regulation of Treg/Th17 cells," Journal of Gastroenterology and Hepatology, vol. 29, no. 8, pp. 1620-1628, 2014.

[19] M. E. M. Amer, S. Z. el-Sayed, W. A. el-Kheir et al., "Clinical and laboratory evaluation of patients with end-stage liver cell failure injected with bone marrow-derived hepatocyte-like cells," European Journal of Gastroenterology \& Hepatology, vol. 23, no. 10, pp. 936-941, 2011.

[20] M. Mohamadnejad, M. Vosough, S. Moossavi et al., "Intraportal infusion of bone marrow mononuclear or $\mathrm{CD} 133^{+}$cells in patients withdecompensated cirrhosis: a double-blind randomized controlled trial," Stem Cells Translational Medicine, vol. 5, no. 1, pp. 87-94, 2016.

[21] H. Salama, A. N. Zekri, A. A. Bahnassy et al., "Autologous $\mathrm{CD}^{+} 4^{+}$and CD133+ stem cells transplantation in patients with end stage liver disease," World Journal of Gastroenterology, vol. 16, no. 42, pp. 5297-5305, 2010.

[22] L. Spahr, Y. Chalandon, S. Terraz et al., "Autologous bone marrow mononuclear cell transplantation in patients with decompensated alcoholic liver disease: a randomized controlled trial," PLoS One, vol. 8, no. 1, article e53719, 2013.

[23] H. Salama, A. R. N. Zekri, R. Ahmed et al., "Assessment of health-related quality of life in patients receiving stem cell therapy for end-stage liver disease: an Egyptian study," Stem Cell Research \& Therapy, vol. 3, no. 6, p. 49, 2012.

[24] T. Cai, Q. Deng, S. Zhang, A. Hu, Q. Gong, and X. Zhang, "Peripheral blood stem cell transplantation improves liver functional reserve," Medical Science Monitor, vol. 21, pp. 1381-1386, 2015.

[25] B. L. Lin, J. F. Chen, W. H. Qiu et al., “Allogeneic bone marrow-derived mesenchymal stromal cells for hepatitis B virus-related acute-on-chronic liver failure: a randomized controlled trial," Hepatology, vol. 66, no. 1, pp. 209-219, 2017.

[26] M. Shi, Z. Zhang, R. Xu et al., "Human mesenchymal stem cell transfusion is safe and improves liver function in acute-on- 
chronic liver failure patients," Stem Cells Translational Medicine, vol. 1, no. 10, pp. 725-731, 2012.

[27] X. Fang, L. Liu, J. Dong et al., "A study about immunomodulatory effect and efficacy and prognosis of human umbilical cord mesenchymal stem cells in patients with chronic hepatitis Binduced decompensated liver cirrhosis," Journal of Gastroenterology and Hepatology, vol. 33, no. 4, pp. 774-780, 2018.

[28] Y. H. Li, Y. Xu, H. M. Wu, J. Yang, L. H. Yang, and W. YueMeng, "Umbilical cord-derived mesenchymal stem cell transplantation in hepatitis B virus related acute-on-chronic liver failure treated with plasma exchange and entecavir: a 24month prospective study," Stem Cell Reviews, vol. 12, no. 6, pp. 645-653, 2016.

[29] X.-P. Tang, X. Yang, H. Tan, Y.-L. Ding, M. Zhang, and W.L. Wang, "Clinical and experimental study on therapeutic effect of umbilical cord blood transplantation on severe viral hepatitis," World Journal of Gastroenterology, vol. 9, no. 9, pp. 1999-2003, 2003.

[30] X. Zhu, B. He, X. Zhou, and J. Ren, "Effects of transplanted bone-marrow-derived mesenchymal stem cells in animal models of acute hepatitis," Cell and Tissue Research, vol. 351, no. 3, pp. 477-486, 2013.

[31] C. Gilsanz, M. A. Aller, S. Fuentes-Julian et al., “Adiposederived mesenchymal stem cells slow disease progression of acute-on- chronic liver failure," Biomedicine \& Pharmacotherapy, vol. 91, pp. 776-787, 2017.

[32] Y. Watanabe, A. Tsuchiya, S. Seino et al., "Mesenchymal stem cells and induced bone marrow-derived macrophages synergistically improve liver fibrosis in mice," Stem Cells Translational Medicine, vol. 8, no. 3, pp. 271-284, 2019.

[33] N. K. Idriss, H. G. Sayyed, A. Osama, and D. Sabry, “Treatment efficiency of different routes of bone marrow-derived mesenchymal stem cell injection in rat liver fibrosis model," Cellular Physiology and Biochemistry, vol. 48, no. 5, pp. 2161-2171, 2018.

[34] K. Takahashi and S. Yamanaka, "Induction of pluripotent stem cells from mouse embryonic and adult fibroblast cultures by defined factors," Cell, vol. 126, no. 4, pp. 663-676, 2006.

[35] M. Baxter, S. Withey, S. Harrison et al., "Phenotypic and functional analyses show stem cell-derived hepatocyte-like cells better mimic fetal rather than adult hepatocytes," Journal of Hepatology, vol. 62, no. 3, pp. 581-589, 2015.

[36] D. C. Hay, D. Zhao, A. Ross, R. Mandalam, J. Lebkowski, and W. Cui, "Direct differentiation of human embryonic stem cells to hepatocyte-like cells exhibiting functional activities," Cloning and Stem Cells, vol. 9, no. 1, pp. 51-62, 2007.

[37] D. C. Hay, J. Fletcher, C. Payne et al., "Highly efficient differentiation of hESCs to functional hepatic endoderm requires ActivinA and Wnt3a signaling," Proceedings of the National Academy of Sciences of the United States of America, vol. 105, no. 34, pp. 12301-12306, 2008.

[38] K. Takayama, M. Inamura, K. Kawabata et al., "Generation of metabolically functioning hepatocytes from human pluripotent stem cells by FOXA 2 and HNF1 $\alpha$ transduction," Journal of Hepatology, vol. 57, no. 3, pp. 628-636, 2012.

[39] K. Cameron, R. Tan, W. Schmidt-Heck et al., "Recombinant laminins drive the differentiation and self-organization of hESC-derived hepatocytes," Stem Cell Reports, vol. 5, no. 6, pp. 1250-1262, 2015.

[40] T. Touboul, N. R. Hannan, S. Corbineau et al., "Generation of functional hepatocytes from human embryonic stem cells under chemically defined conditions that recapitulate liver development," Hepatology, vol. 51, no. 5, pp. 1754-1765, 2010.

[41] S. J. I. Blackford, S. S. Ng, J. M. Segal et al., "Validation of current good manufacturing practice compliant human pluripotent stem cell-derived hepatocytes for cell-based therapy," Stem Cells Translational Medicine, vol. 8, no. 2, pp. 124-137, 2019.

[42] D. G. Phinney and M. F. Pittenger, "Concise review: MSCderived exosomes for cell-free therapy," Stem Cells, vol. 35, no. 4, pp. 851-858, 2017.

[43] L. Chen, C. Zhang, L. Chen et al., "Human menstrual bloodderived stem cells ameliorate liver fibrosis in mice by targeting hepatic stellate cells via paracrine mediators," Stem Cells Translational Medicine, vol. 6, no. 1, pp. 272-284, 2017.

[44] V. Sood, B. R. Mittal, A. Bhansali et al., "Biodistribution of 18F-FDG-labeled autologous bone marrow-derived stem cells in patients with type 2 diabetes mellitus: exploring targeted and intravenous routes of delivery," Clinical Nuclear Medicine, vol. 40, no. 9, pp. 697-700, 2015.

[45] E. Ragni, F. Banfi, M. Barilani et al., "Extracellular vesicle-shuttled mRNA in mesenchymal stem cell communication," Stem Cells, vol. 35, no. 4, pp. 1093-1105, 2017.

[46] C. Zhou, B. Yang, Y. Tian et al., "Immunomodulatory effect of human umbilical cord Wharton's jelly-derived mesenchymal stem cells on lymphocytes," Cellular Immunology, vol. 272, no. 1, pp. 33-38, 2011.

[47] M. L. Weiss, C. Anderson, S. Medicetty et al., "Immune Properties of Human Umbilical Cord Wharton's Jelly-Derived Cells," Stem Cells, vol. 26, no. 11, pp. 2865-2874, 2008. 


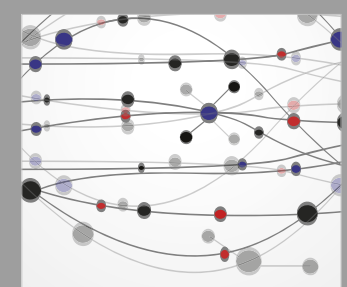

The Scientific World Journal
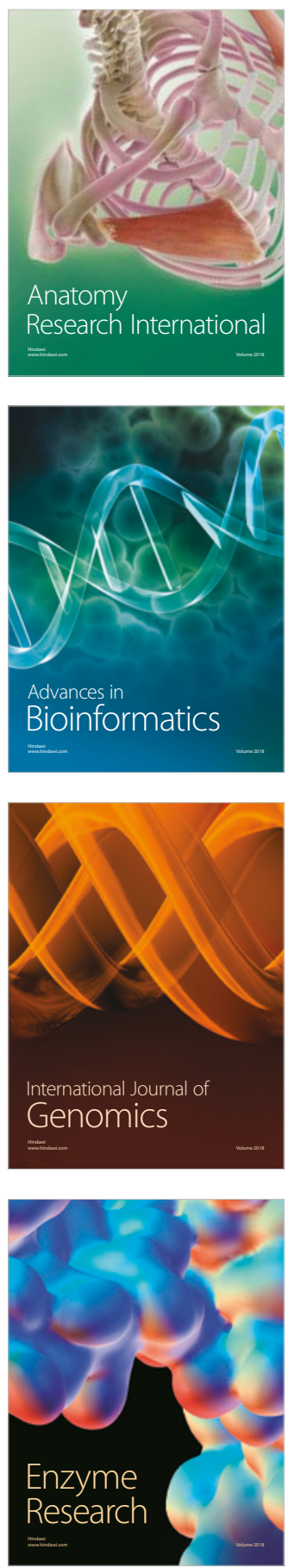
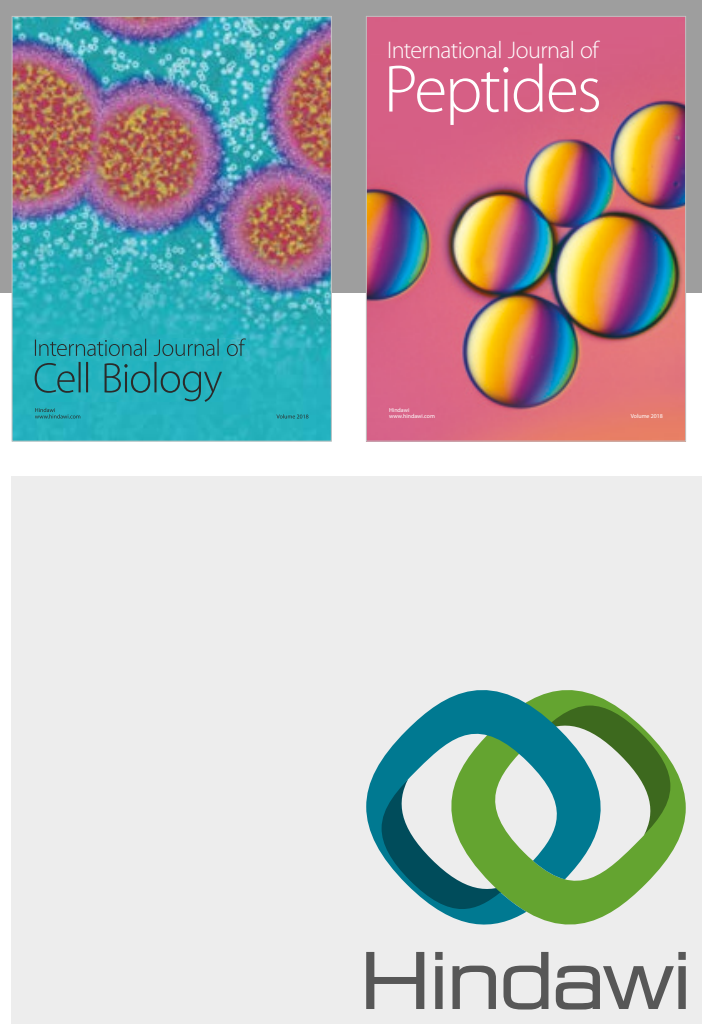

Submit your manuscripts at

www.hindawi.com
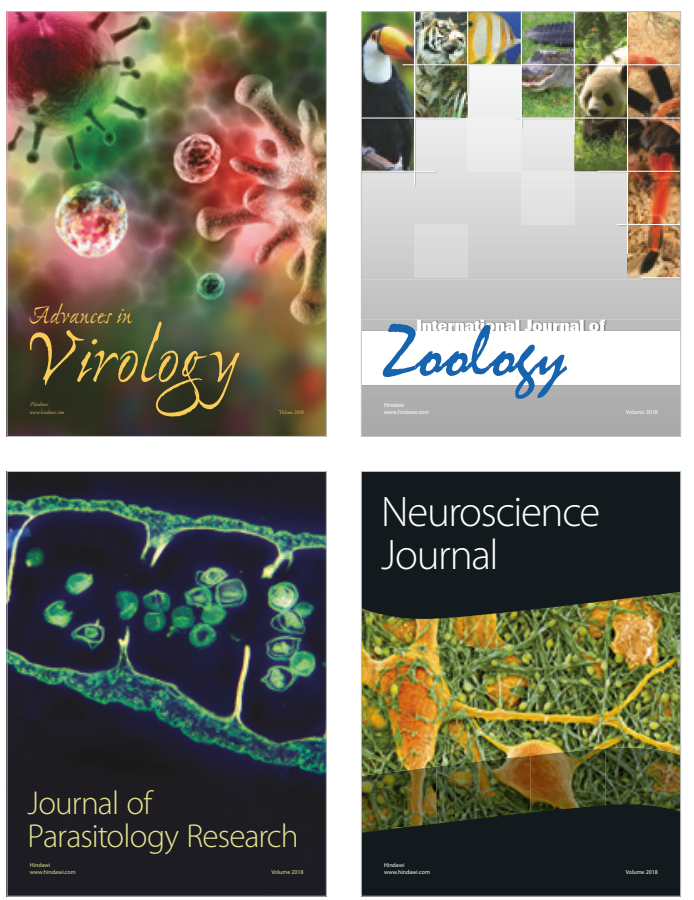
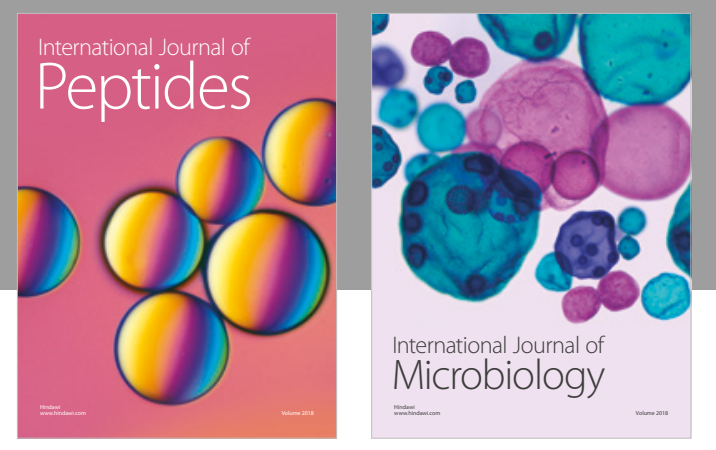

nternational Journal of Microbiology
Journal of
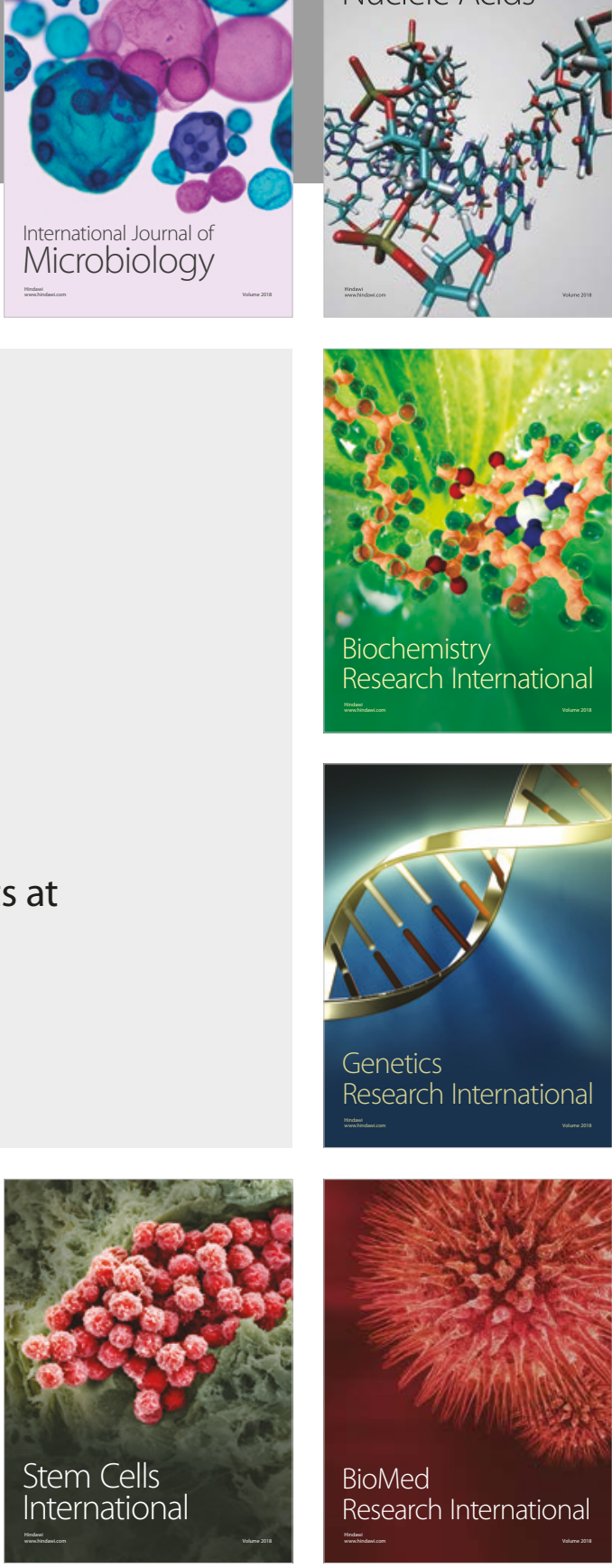
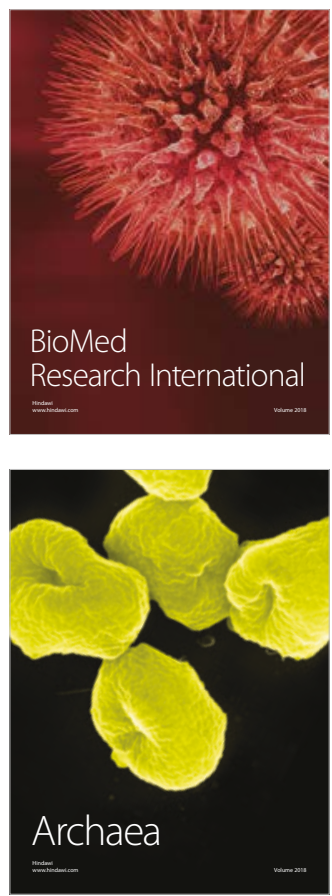